Article

\title{
Loading Capacity and Deformation Characteristics of Tailings Based on a Fractal Geometrical Analysis of the Particle Microstructure
}

\author{
Qiangui Zhang ${ }^{1,2,3, *}$, Guangzhi Yin ${ }^{3}$, Xiangyu Fan ${ }^{1,2}$, Zuoan Wei ${ }^{3}$, Wensong Wang ${ }^{3}$ and \\ Wen Nie ${ }^{3, *}$
}

1 State Key Laboratory of Oil and Gas Reservoir Geology and Exploitation, Southwest Petroleum University, Chengdu 610500, Sichuan, China; E-Mail: fanxy666@swpu.edu.cn

2 School of Oil \& Natural Gas Engineering, Southwest Petroleum University, Chengdu, Sichuan 610500, China

3 State Key Laboratory of Coal Mine Disaster Dynamics and Control, Chongqing University, Chongqing 400044, China; E-Mails: gzyin@cqu.edu.cn (G.Y.); weiza@cqu.edu.cn (Z.W.); sdgxwws@163.com (W.W.)

* Authors to whom correspondence should be addressed; E-Mails: qgzhang@swpu.edu.cn (Q.Z.); niewen1026@gmail.com (W.N.); Tel.: +86-28-8303-7050 (Q.Z.); +49-176-3119-9092 (W.N.).

Academic Editor: Karen Hudson-Edwards

Received: 22 October 2014 / Accepted: 27 January 2015 / Published: 3 February 2015

\begin{abstract}
The failure of a tailing dam occurs due to damage to the particles' micro-structure. Understanding the deformation characteristics of the particle' micro-structure is important for understanding the mechanics of instability in tailing dams. In our study, a series of experiments was conducted using a testing apparatus for micro-mechanics and the deformation of tailings from the Huangcaoping tailing pond, Sichuan Province, China to investigate the loading capacity, micro-structure and deformation features of tailing particles. The latter two were analyzed quantitatively using concepts from fractal geometry. The results demonstrate that: (1) the structural loading capacity of tailings increases first and then decreases slightly with increasing particle size; (2) the particle micro-structure of the four tailing samples from the Huangcaoping tailing pond is described in terms of the fractal dimension based on the perimeter and area ( $D$-value), which is between 1.288 and 1.533 ; (3) as the axial stress increases, the $D$-value gradually decreases along a wavy line with a decreasing rate of change; (4) under the same axial strain, the $D$-value first
\end{abstract}


decreases and later increases slightly as the particle size increases; and (5) the number of fractured particles increases with the particle size.

Keywords: tailings; granular matter; micro-structure; loading capacity; fractal theory

\section{Introduction}

When a greater than critical amount of stress is applied to soil, the soil deforms over time. One of the major factors affecting this deformation is the soil's structural strength $[1,2]$. The structural strength is closely related to the soil's micro-structural features, such as the size, shape, orientation and aggregation of the soil particles [3]. Essentially, the macro-structural instability of the soil reflects the accumulated deformations of its microstructure [4]. Therefore, to investigate the relationship between deformation and the structural strength of a soil, some researchers have suggested taking a microscopic view [5]. Micro-deformations of soil include structural changes in particle aggregation and changes in the shapes of individual particles. The former changes occur when particles move or rotate and the latter changes are caused by compressive, shear and tensile stresses [6]. Fractal geometry is useful for describing mutability, roughness and self-similarity [7] and has privileged connections with non-extensive statistical mechanics [8]. Concepts from fractal geometry have been widely used to describe complex natural phenomena, including the mechanics of rocks and soils [9-17]. The sizes of particles resulting from comminution are properly described by a fractal size distribution $[18,19]$, which leads to a power-law slope in a double-logarithmic plot. The fractal dimension of the particle size distribution (PSD) decreases as the sand content increases [20]. High PSD fractal dimensions are usually attributed to abrasive processes related to large strains or high strain rates [21]. The fragmentation fractal dimension increases with the degree of breakage [22]. To summarize, fractal geometry has been widely used to study soil particle size distributions, but very little research into soil micro-structures has been performed.

The tailing dam addressed in this study is constructed from tailings and built on a tailing beach [23]. The effect of gravity on the superstratum of this tailing dam could cause changes in the micro-structure of the tailing beach. Once the deformation of the tailings' micro-structure reaches a critical point, the tailing dam may break down. However, the size, shape and physical and chemical properties of tailings are quite different from those of soil [24]. Therefore, it is necessary to study these properties quantitatively with the aid of fractal geometry, a technique that has been successful in soil research. Unfortunately, few researchers have studied the micro-structural characteristics of tailing particles [25]. In the present work, a series of experiments was performed using a "testing apparatus for micro-mechanics and deformation of tailings" to investigate the loading capacity characteristics, micro-structure and deformation features of tailing particles. This research is highly important for understanding the mechanisms of tailing dam failure.

\section{Theoretical Basis: Fractal Geometry}

The profile of a tailing particle, which is a rough, closed, irregular pattern, can be described using the notions of perimeter and area in fractal geometry [26]. The perimeter and area of a shape in 
two-dimensional space are related to one another by a power law. The exponent of this power law is associated with, but does not necessarily provide, an unbiased estimate of the fractal dimension based on the perimeter and area ( $D$-value) [27]. For a regular pattern, the perimeter $(P)$ is proportional to a measurement $(\varepsilon)$, and the area $(A)$ is proportional to the square of this measurement $\left(\varepsilon^{2}\right)$. Thus, the relation of $P$ and $A$ can be expressed as:

$$
P \propto A^{\frac{1}{2}}
$$

Mandelbrot noted that it is reasonable to use the fractal perimeter and area when describing an irregular perimeter and area in two dimensions [28]. Therefore, Equation (1) can be rewritten in terms of the measurement $(\varepsilon)$ as:

$$
(P(\varepsilon))^{\frac{1}{D}}=a_{0} \varepsilon^{\frac{1-D}{D}}(A(\varepsilon))^{\frac{1}{2}}=a_{0} \varepsilon^{\frac{1}{D}-1}(A(\varepsilon))^{\frac{1}{2}},
$$

where $P(\varepsilon)$ and $A(\varepsilon)$ are the perimeter and area, respectively, in terms of the measurement $(\varepsilon)$, and $a_{0}$ is a constant that is related to the shape of the pattern. $D$ is the fractal dimension of the pattern. Equation (3) is obtained by taking the logarithm of Equation (2):

$$
\frac{\lg [P(\varepsilon) / \varepsilon]}{D}=\lg a_{0}+\lg \left[\frac{(A(\varepsilon))^{\frac{1}{2}}}{\varepsilon}\right]
$$

When $\lg [P(\varepsilon) / \varepsilon]$ and $\lg \left[A(\varepsilon)^{1 / 2} / \varepsilon\right]$ are graphed in Cartesian coordinates, a linear relationship indicates that the pattern has fractal characteristics; the slope of the straight line is its $D$-value. To reduce the tedious process of defining $\varepsilon$, the pattern is assumed to have statistical self-similarity. Therefore, the approximate perimeter $(P)$ and area $(A)$ of a particle can be calculated from a specific measurement $(\varepsilon)$, and thus, Equation (3) reduces to Equation (4) when the measurement $(\varepsilon)$ is regarded as "one" [29]:

$$
\lg A=\frac{2}{D} \lg P-\lg a_{0}^{2}
$$

Thus, a straight line can be obtained by fitting $\lg P$ and $\lg A$ in Cartesian coordinates, and the fractal dimension ( $D$-value) can be calculated using Equation (5) [30]:

$$
D=\frac{2}{K}
$$

where $K$ is the slope of the best-fit line.

\section{Equipment, Materials and Methods}

\subsection{Equipment}

A "testing apparatus for micro-mechanics and deformation of tailings" (Figure 1) [4] was employed in the tests. The experimental apparatus measures the deformation of the tailings' micro-structure and the motion of the tailing particles in different stress fields, with the aim of revealing the deformations of the tailings' micro-structure under the gravitational force of tailings farther up in the dam. The experimental apparatus consists of a testing machine, a pressure vessel and a microscopic 
observation system. A structural diagram of the apparatus is shown in Figure 2. The main technical indexes of the apparatus are given in Table 1.

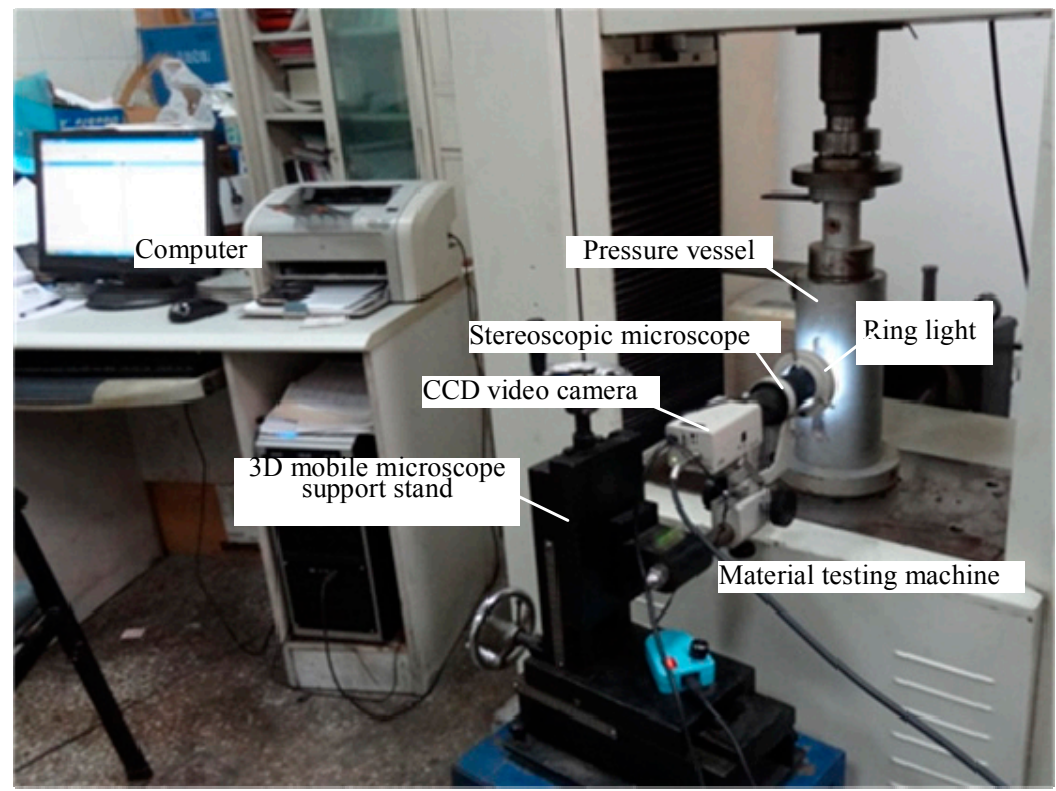

Figure 1. The testing apparatus.

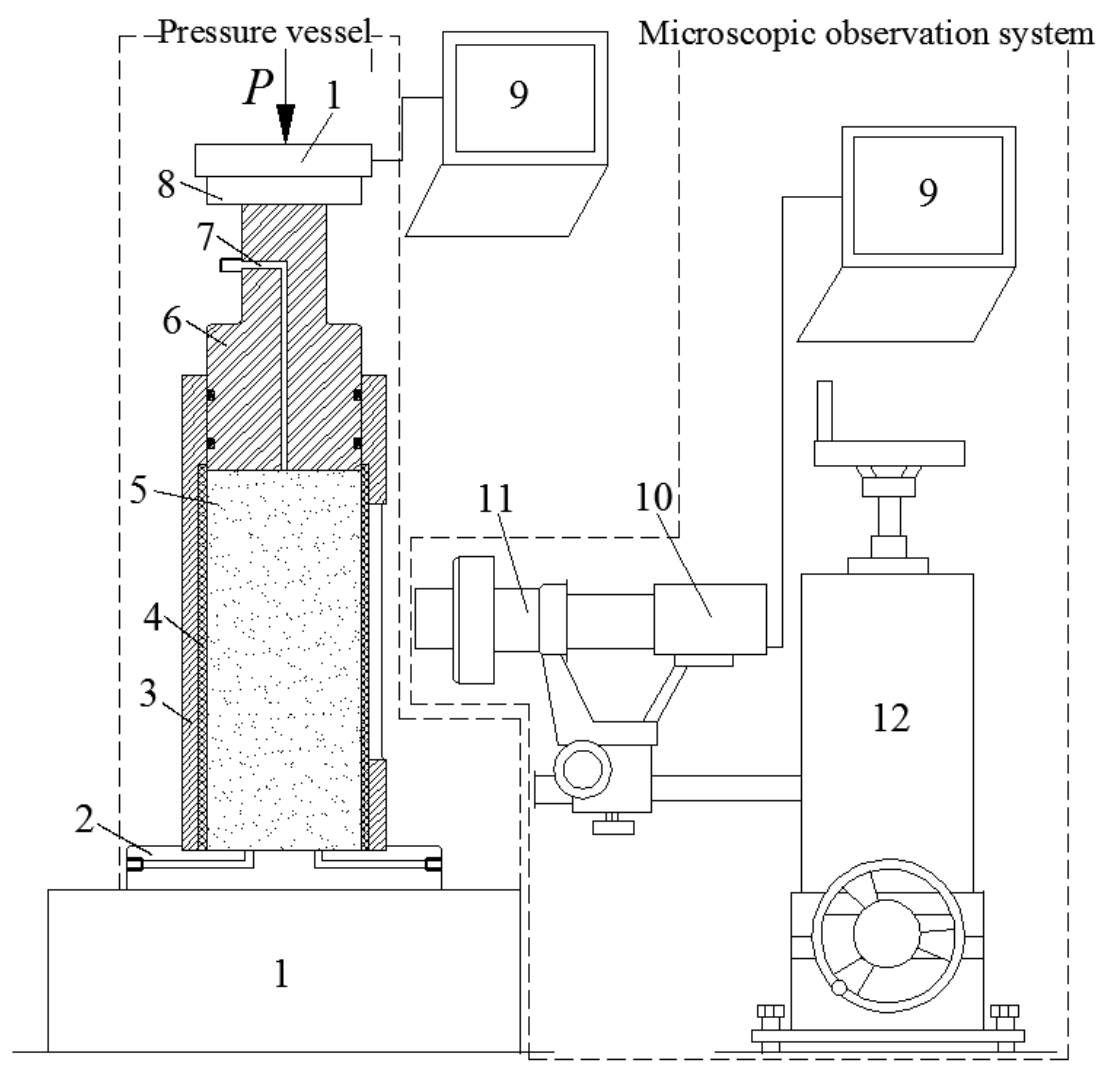

Figure 2. The testing apparatus: 1, testing machine; 2, bottom plate; 3, stainless steel cylinder; 4, tempered glass cylinder; 5, tailing specimen; 6, pressure piston; 7, exhaust hole; 8, piston pressure head; 9, computer; 10, CCD (Charge Coupled Device) video camera; 11, stereoscopic microscope; 12, 3D mobile microscope support stand. 
Table 1. Technical parameters of the apparatus.

\begin{tabular}{|c|c|c|c|c|c|c|c|}
\hline \multicolumn{3}{|c|}{ Material Creep Testing Machine } & \multicolumn{3}{|c|}{ Pressure Chamber } & \multicolumn{2}{|c|}{ Soil Pressure Sensor } \\
\hline Maximum load/kN & Sensitivity/N & $\begin{array}{c}\text { Load } \\
\text { proportion }\end{array}$ & $\begin{array}{c}\text { Pressure head } \\
\text { maximum stroke/mm }\end{array}$ & $\begin{array}{c}\text { Specimen } \\
\text { size } / \mathrm{mm} \times \mathrm{mm} \\
\end{array}$ & $\begin{array}{l}\text { Maximum } \\
\text { pressure }\end{array}$ & $\begin{array}{c}\text { Measurement } \\
\text { range } / \mathrm{kPa} \\
\end{array}$ & Sensitivity $/ \mathrm{kPa}$ \\
\hline 30 & 0.1 & $1: 250$ & 50 & $\varphi 100 \times 200$ & $2.5 \mathrm{MPa}$ & $100-1500$ & 10 \\
\hline \multicolumn{8}{|c|}{ Microscopic observation system } \\
\hline Total amplifier rate & \multicolumn{2}{|c|}{ Field range/mm } & Working distance $/ \mathrm{mm}$ & $\begin{array}{c}\text { Microscope } \\
\text { regulation range } / \mathrm{mm}\end{array}$ & \multicolumn{2}{|c|}{$\begin{array}{c}\text { Vertical bars regulation } \\
\text { range } / \mathrm{mm}\end{array}$} & $\begin{array}{c}\text { Working face } \\
\text { maximum height } / \mathrm{mm}\end{array}$ \\
\hline $7 \sim 180$ & \multicolumn{2}{|c|}{$30.77 \sim 4.44$} & 100 & 43 & \multicolumn{2}{|r|}{80} & 120 \\
\hline
\end{tabular}

\subsection{Materials}

Four types of iron tailings with different particle sizes, which were labeled I, II, III and IV, were collected from the tail of the crest of the Huangcaoping tailing pond dam belonging to the Pingchuan Iron Co. Ltd. in Yanyuan County, Sichuan Province, China. The dry density was $1.35-1.37 \mathrm{~g} / \mathrm{cm}^{3}$ for Sample I, $1.37-1.39 \mathrm{~g} / \mathrm{cm}^{3}$ for Sample II, $1.37-1.40 \mathrm{~g} / \mathrm{cm}^{3}$ for Sample III and $1.38-1.41 \mathrm{~g} / \mathrm{cm}^{3}$ for Sample IV. The moisture content was $8.36 \%-8.78 \%$ for Sample I, $8.54 \%-8.98 \%$ for Sample II, 9.02\%-9.78\% for Sample III and $9.57 \%-10.02 \%$ for Sample IV. These values were obtained by in situ testing when we collected the samples. All of the samples were dispersed to single particles with an ultrasonic cleaner, and then, their particle sizes were determined using an S3500 light-scattering particle size analyzer made by Microtrac Inc., Montgomeryville, PA, USA. The tailings' PSD is shown in Figure 3. Detailed parameters, including the characteristic particle size and other physical properties, are listed in Table 2. Some of the chemical properties of the iron tailings were analyzed by XRF (X-Ray Fluorescence Spectrometer); the results are listed in Table 3.

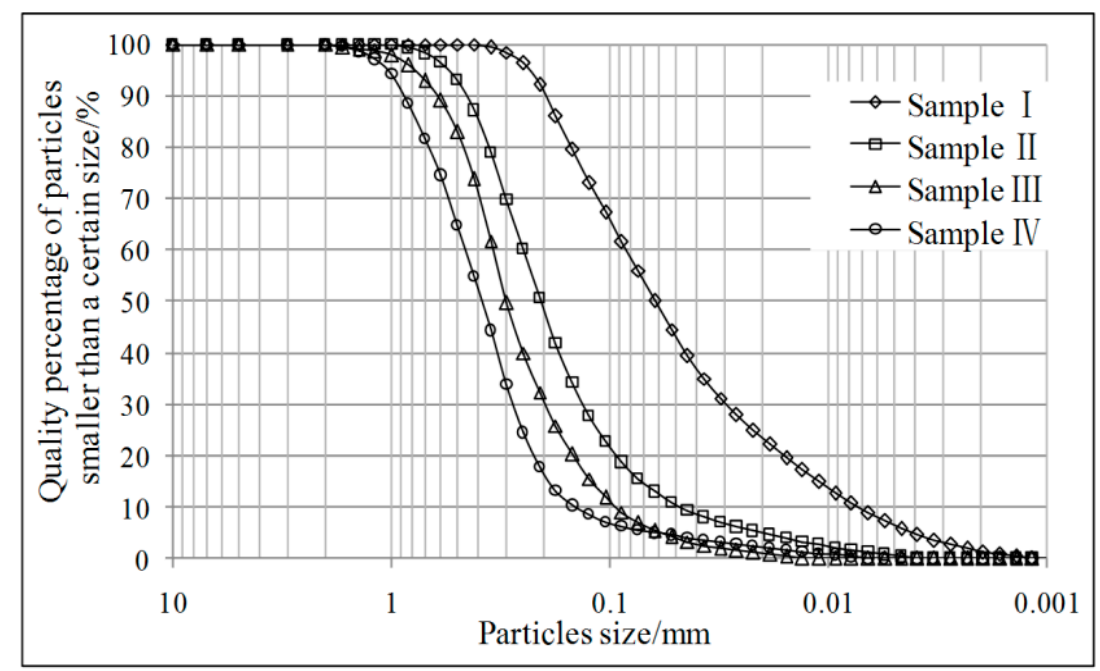

Figure 3. Particle size distribution (PSD) of the tailings.

The four tailing samples had an average moisture content of $9 \%$ and a dry density of $1.38 \mathrm{~g} / \mathrm{cm}^{3}$. The tailing samples were made into cylinders of $\Phi 100 \mathrm{~mm} \times \mathrm{L} 200 \mathrm{~mm}$ layer by layer in a pressure vessel. To ensure natural contact between the particles, the interface between each pair of tailing layers was scratched with a knife [31]. Each specimen was divided into 5 layers to allow the tailings to be 
dispersed uniformly. Each layer weighed $472.3 \mathrm{~g}$ and was $40 \mathrm{~mm}$ thick after being compacted by a pressure plate. Next, the pressure piston was pushed into the pressure chamber with the exhaust valve open until it contacted the specimen. Finally, the exhaust and drain valves of the apparatus were closed.

Table 2. PSD parameters and main physical indexes of the tailings.

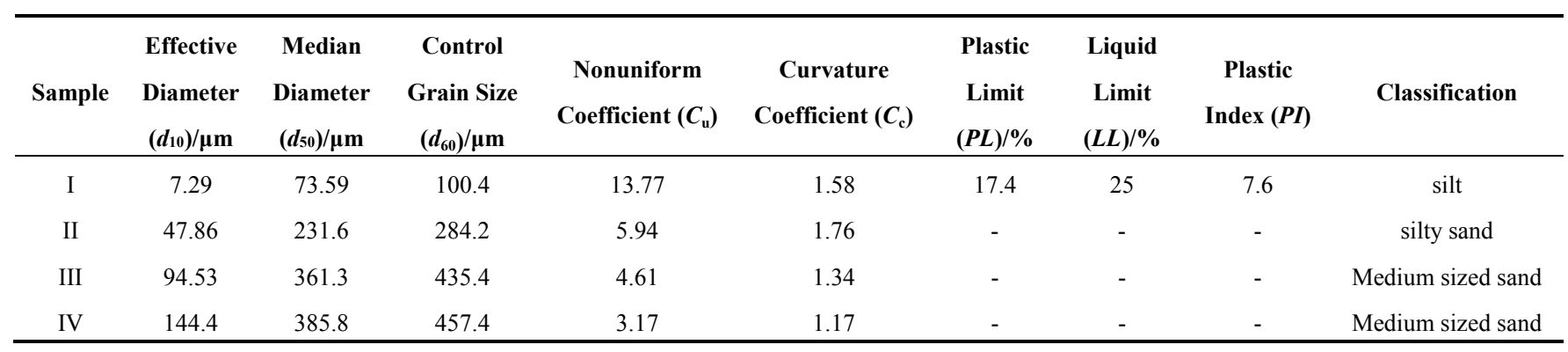

Table 3. Chemical properties of the iron tailings.

\begin{tabular}{cc}
\hline Property & Results \\
\hline $\mathrm{pH}^{\mathrm{a}}$ & 7.19 \\
Analyzed by XRF & Unit $=\mathrm{mg} / \mathrm{kg}$ \\
Oxygen & $411,928.2$ \\
Fluorine & $3,165.5$ \\
Phosphorus & 531.4 \\
Sulfur & $5,496.2$ \\
Titanium & $3,163.8$ \\
Copper & $5,642.4$ \\
Zinc & 218.5 \\
Arsenic & $1,940.6$ \\
Rubidium & 282.9 \\
Strontium & 258.1 \\
Stibium & 567.4 \\
Barium & 109.4 \\
Lead & 177.2 \\
Bismuth & 139.1 \\
Stannum & $2,805.2$ \\
Silicon & 132,678 \\
Aluminum & $18,341.7$ \\
Iron & $229,218.2$ \\
Magnesium & $13,302.9$ \\
Calcium & $83,622.22$ \\
Natrium & 363.8 \\
Kalium & $7,355.1$ \\
Carbon & 6,150 \\
Other component & $72,542.2$ \\
\hline Note $a$ & \\
\hline
\end{tabular}

Note: ${ }^{\text {a }}$ Soil/water ratio $1: 1$. 


\subsection{Measurement}

A continuous dynamic load was applied by an AG-250kNI material testing machine (Shimadzu Corporation, Kyoto, Japan) at a loading rate of $0.5 \mathrm{~mm} / \mathrm{min}$. The maximum axial strain and stress were set to $12 \%$, which is equivalent to $2.5 \mathrm{MPa}$, according to the apparatus' specifications. During testing, the axial strain and stress were monitored simultaneously, and the micro-structures of the tailings were captured at 5-min intervals. The specific methods used for each sample were as follows:

(1) Installation of the pressure vessel

After the pressure vessel was put onto the platform of the AG-250kNI material testing machine, the loaded plate was adjusted, so that it touched the piston pressure head. The microscopic observation device was installed alongside the pressure vessel; the stereoscopic microscope's lens was aimed at the observation window; and the lens' focal length and the image software were adjusted to improve the observations. The complete apparatus, prepared for testing, is shown in Figure 1.

(2) Testing

First, an image of the specimen's micro-structure with a length of $750 \mu \mathrm{m}$ and a width of $600 \mu \mathrm{m}$ near the $100 \mathrm{~mm}$ mark in the observation window was captured. Next, the drained loading test was performed by the AG-250kNI material testing machine at a rate of $0.5 \mathrm{~mm} / \mathrm{min}$ with the exhaust hole open. The axial strain and stress were monitored throughout the test. The 3D mobile microscope observation support stand was adjusted to ensure that the lens was focused on the initial micro-structure; images were captured at 5-min intervals. The test was stopped when the axial strain or stress reached the set value.

The tests performed on Samples II, III and IV also followed these steps. The experimental procedure for each tailing sample is shown in Figure 4.

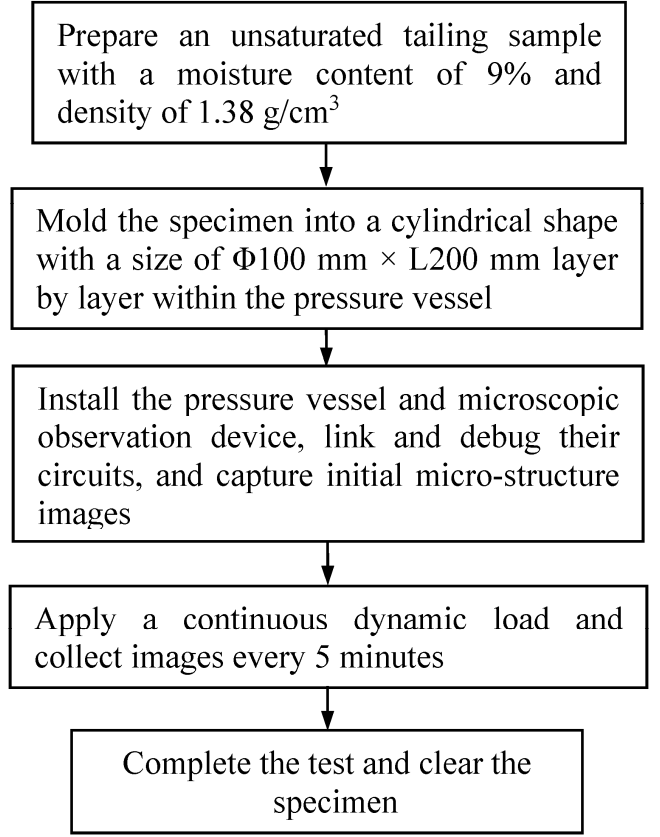

Figure 4. Experimental procedure for each tailing sample. 


\subsection{Obtaining the Eigenvalues of the Images}

Obtaining the approximate perimeter and area of the tailing particles is the key part of this method; it involves three steps: (1) transform the image into a grayscale image; (2) differentiate between particles and pores; and (3) calculate the perimeter and area of the tailing particles. The most important step is choosing an accurate threshold binarization value (eigenvalue) for differentiating between particles and pores to determine an exact $D$-value that describes the tailings' micro-structure. Because of the intermediate colors in the image, the threshold value should be adjusted to filter out the demitint between particles and pores; the threshold value choice can clearly affect the calculated particle morphology. The CF-2000P polarized light analysis program (Shanghai Changfang Optical Instrument Co. Ltd., Shanghai, China) was used to analyze the images. This software can transform a color image into a grayscale image, obtain the binary image and calculate the approximate perimeter and area of a tailing particle.

\section{Results}

\subsection{Loading Capacity of the Tailings}

The loading capacity of the tailings observed by monitoring the axial stress and strain is closely related to the particle size, as shown in Figure 5. The lateral deformation is restricted in this compression test, which can reveal the stress and strain on the undamaged tailing dam. In general, the axial stresses of the four samples improve as the axial strain increases, and so do their increments. The axial stress of Sample I is smaller than that of the other samples. The axial stress of Sample II is the same as those of Samples III and IV when the axial strain is less than $2.5 \%$. When the axial strain is greater than $2.5 \%$, the axial stress of Sample II is less than those of Samples III and IV, and the difference increases with increases in the axial strain. The axial stresses of tailing Samples III and IV are almost the same when the axial strain is less than 5\%; however, when the axial strain is greater than $5 \%$, the axial stress of Sample III becomes greater than that of Sample IV, and the difference increases with the axial strain. In summary, the particle size has a significant influence on the loading capacity of the tailings, which has no obvious regularity when the axial strain is small. When the axial strain reaches a certain value, the loading capacity first increases with the particle size and then decreases slightly. The decrease is apparent at high axial strains, as shown in Figure 6.

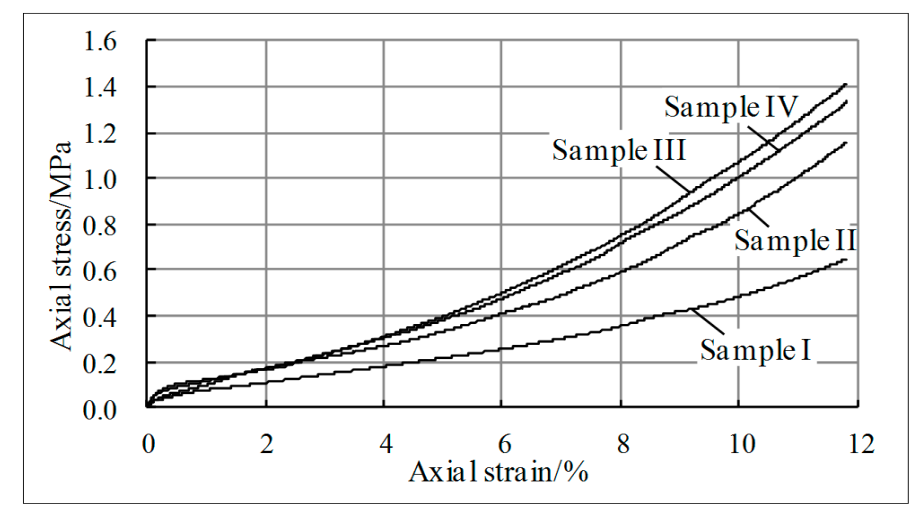

Figure 5. Curves of the axial stress and strain of the tailing specimens. 


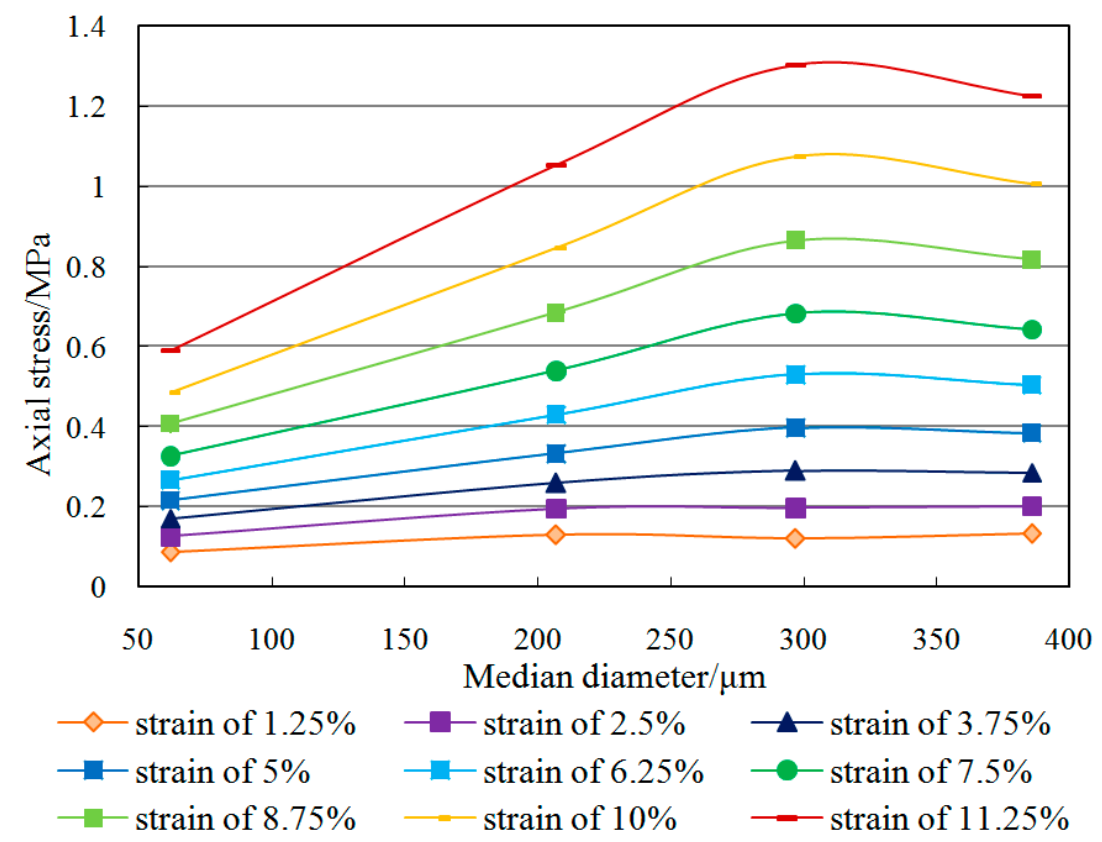

Figure 6. Axial stress versus median particle diameter under different strains.

\subsection{Fractal Features of the Particle Micro-Structures}

The micro-structure of Sample IV without an applied load is shown in Figure 7a. The binary image shown in Figure $7 \mathrm{~b}$ was obtained using the CF-2000P polarized light analysis software and the method described in Section 3.4. The threshold values were determined artificially as 122 for R (red), 137 for $\mathrm{G}$ (green) and 138 for B (blue). The black portion of the image represents the 104 particles (as calculated by the software), and the white portion represents the pores. The approximate perimeter and area of the particles were calculated by the software. Figure 8 shows the relationship between the approximate perimeter and area of the particles in the image. These results indicate that the particles' micro-structure has features typical of fractals, and the $D$-value of this image calculated using Equation (5) is 1.393 with a relative coefficient $\left(R^{2}\right)$ of 0.936 . The $D$-values of the 59 images of the four samples were obtained by the same methods; they are between 1.288 and 1.533 with relative coefficients $\left(R^{2}\right)$ between 0.919 and 0.965 .

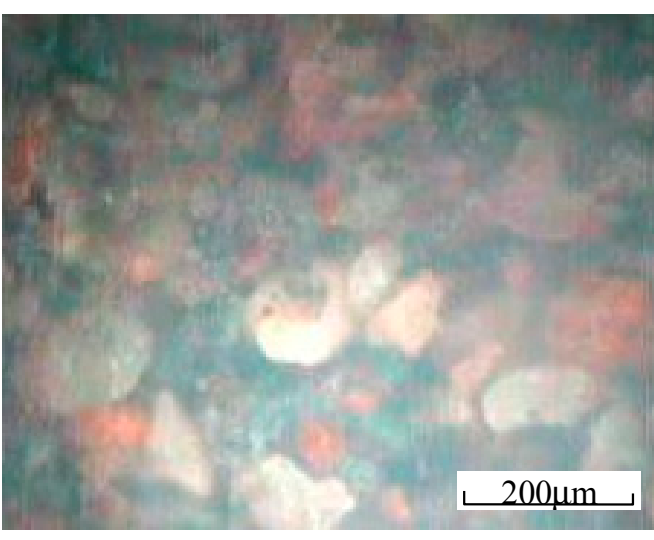

(a)

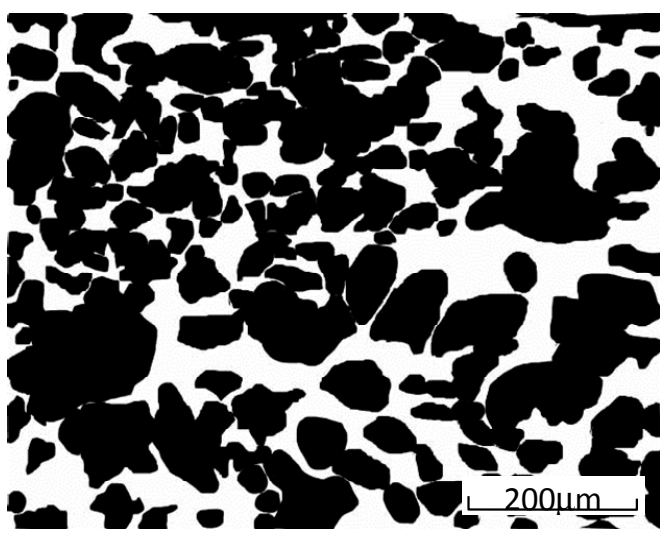

(b)

Figure 7. Micro-structure of Sample IV without an applied load. (a) Original image; (b) binary image. 


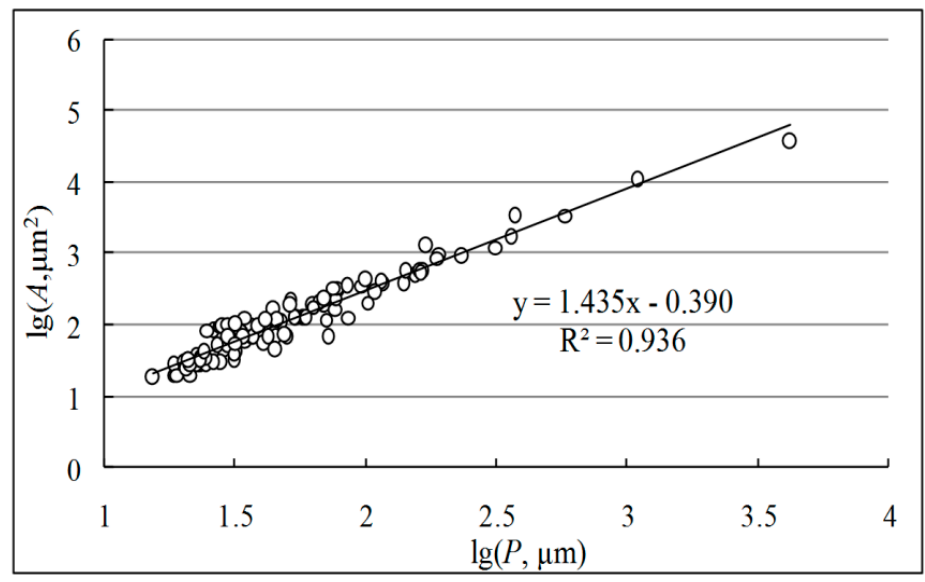

Figure 8. Relationship between the approximate perimeter and area of the particles.

\subsection{Deformation Features of the Particles' Micro-Structure under Load}

Taking Sample IV as an example, the image area of the micro-structure was defined by the edges of Particles A and B, as shown in Figure 9. The 3D mobile microscopy observation support stand was adjusted accordingly, so that it focused on the defined area. The micro-structures of the tailings at axial strains of $2.5 \%, 5 \%, 7.5 \%$ and $10 \%$ are presented in Figure 9, which clearly reveals that the distances between Particles A and C are 107.36, 91.24, 88.46 and $65.86 \mu \mathrm{m}$ at these axial strains, respectively, indicating that the micro-structure of the tailings changes significantly under load and that the pore size decreases nonlinearly with increasing axial strain. Furthermore, the characteristics of the particles change significantly: (1) particles rotate under stress, so that their long axes approach the best shear direction [32], as shown, for example, by the deflection of Particle D; (2) particles are crushed when the axial strain increases, especially particles with high major to minor axis ratios, such as Particle E; this particle crushing may reduce the anisotropic shear strength of the tailings [33]; and (3) two particles can be combined and viewed as one large particle during the binarization process, as Particles $\mathrm{E}$ and $\mathrm{F}$ are.

The $D$-values of the different samples differ significantly. Figure 10 shows how the $D$-value changes with the median particle diameter. The ranges of the variations in the $D$-values of Samples I, II, III and IV are $1.533-1.402,1.445-1.364,1.428-1.330$ and $1.423-1.370$, respectively. Under the same axial strain, the $D$-value first decreases and then increases slightly as the particle size increases. The decrease becomes smaller and the increase becomes larger as the axial strain increases. For instance, the decrease is $6.83 \%$, and the increase is $0.65 \%$ when the axial strain is $1.25 \%$; however, the figures change to $3.39 \%$ and $3.02 \%$ when the axial strain is $11.25 \%$.

The $D$-values of particles under different stresses are shown in Figure 11. As the axial stress increases, the $D$-value gradually decreases at a dwindling rate. In Sample I, for example, the $D$-values for stresses of 0.212 and $0.268 \mathrm{MPa}$ are 1.451 and 1.461 , respectively, the latter of which is an increase of $0.69 \%$ compared with the former. It can also be observed that the $D$-values change irregularly under the high stresses of $0.403,0.503,0.599$ and $0.730 \mathrm{MPa}$. Although the change of the $D$-value is very complex, the general trend between the $D$-value and the axial stress can be fitted to a quadratic polynomial. The best-fit formulas are shown in Table 4 , and their relative coefficients $\left(R^{2}\right)$ are between 0.882 and 0.949. The best-fit polynomials describing the relationship between the $D$-values and stress apply to stresses in a particular range. 


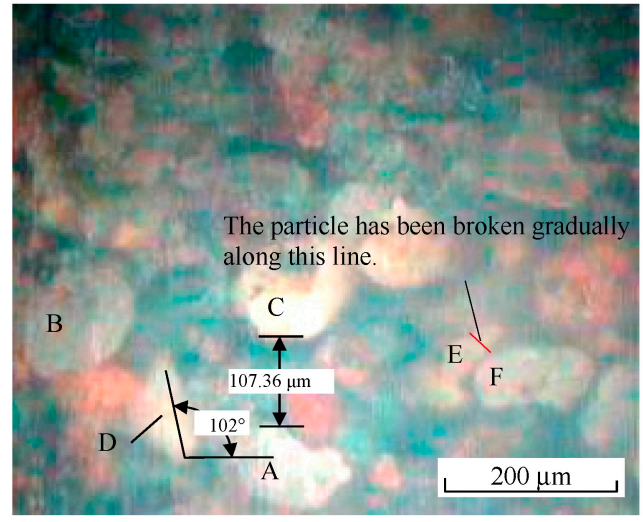

(a)

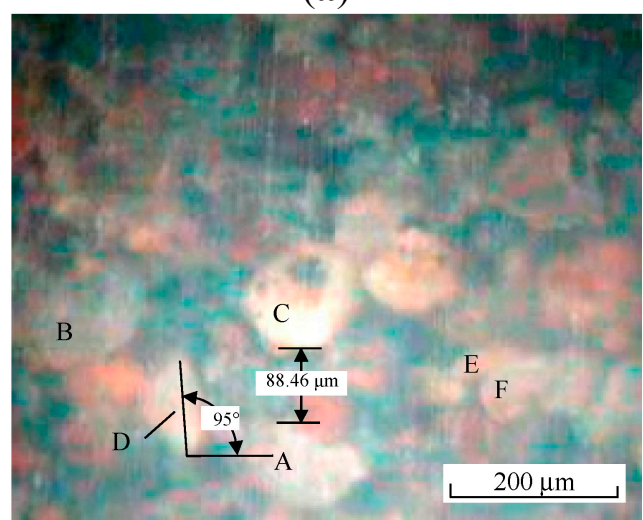

(c)

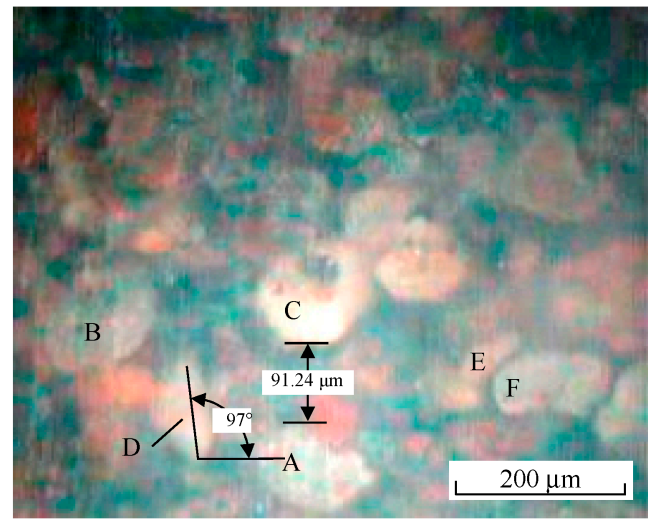

(b)

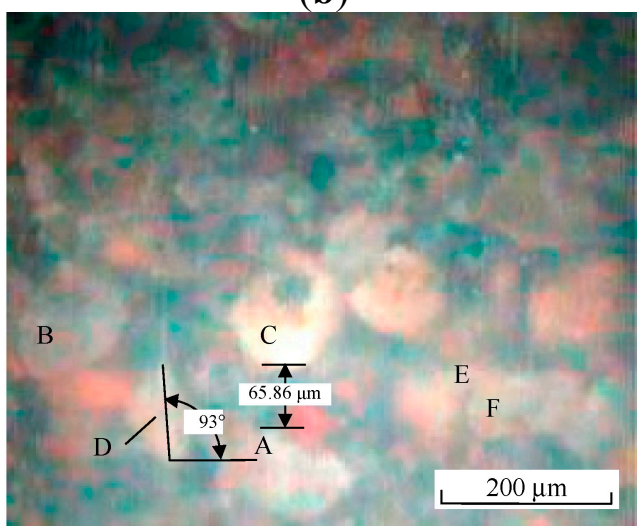

(d)

Figure 9. Micro-structure of Sample IV at different axial strains. (a) 2.5\% axial strain; (b) 5\% axial strain; (c) $7.5 \%$ axial strain; (d) 10\% axial strain.

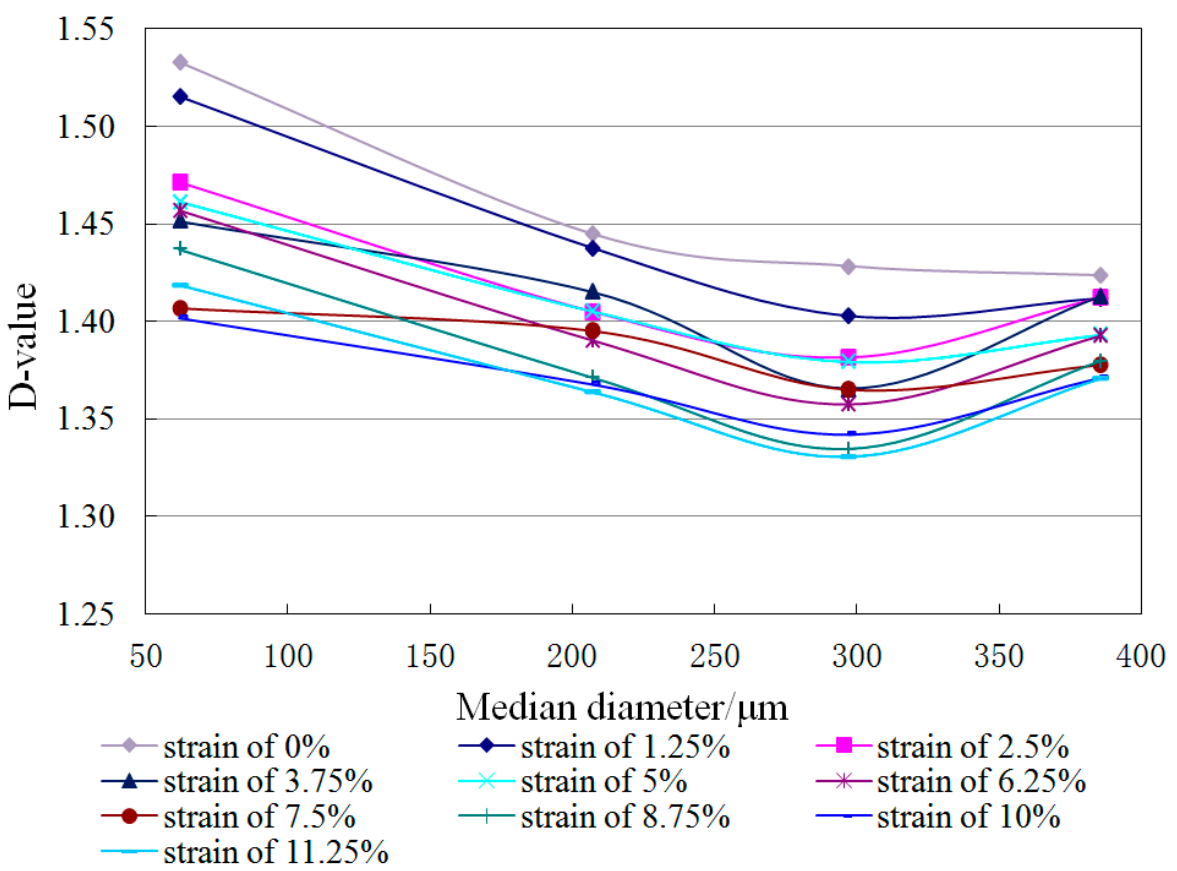

Figure 10. $D$-values for different tailings. 


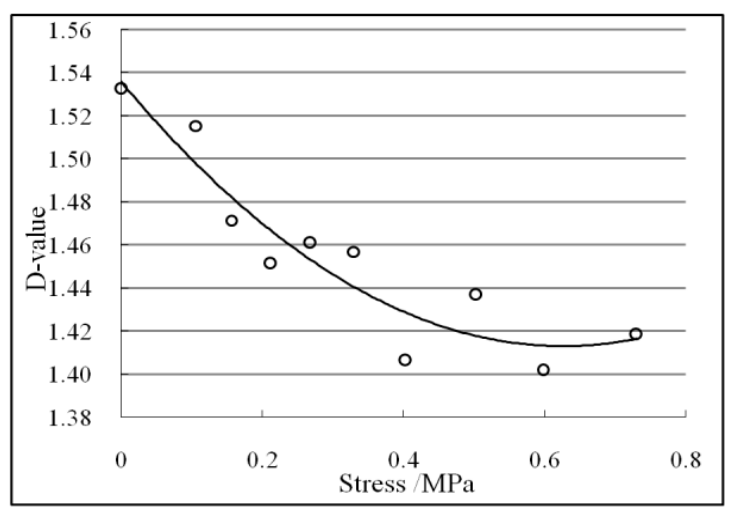

(a)

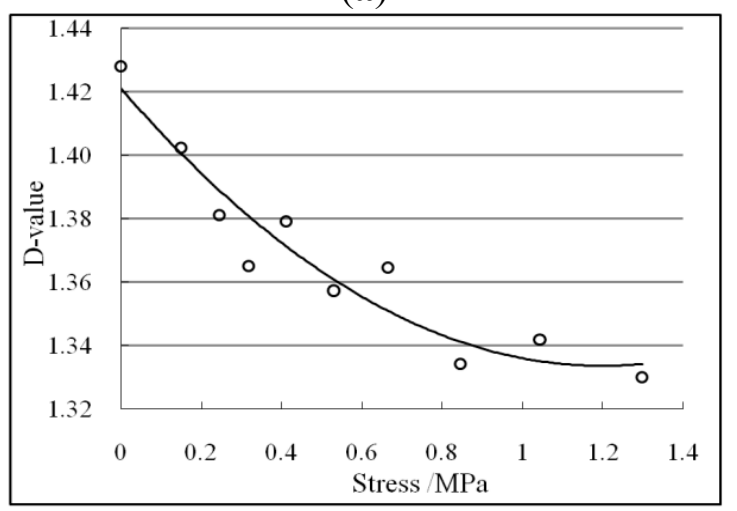

(c)

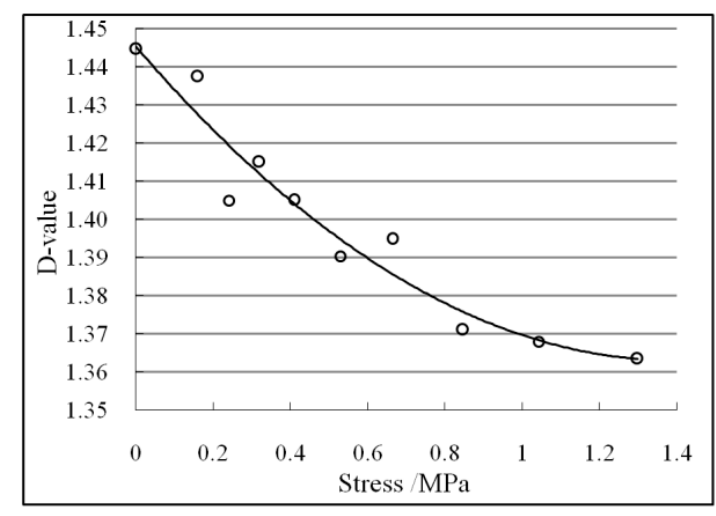

(b)

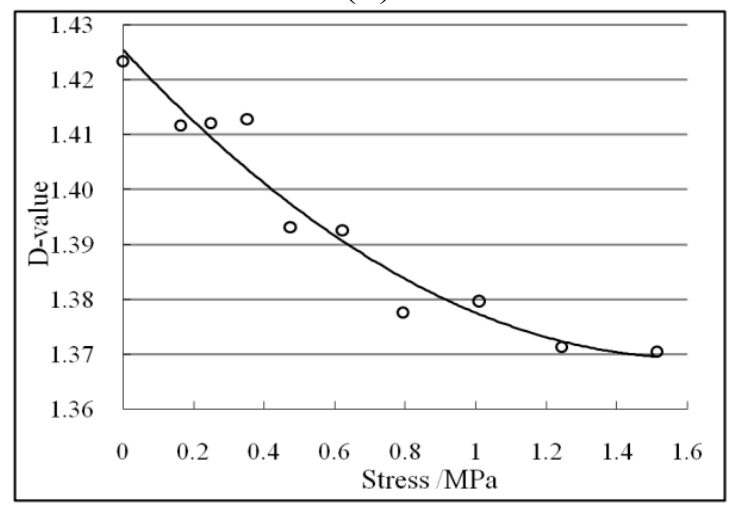

(d)

Figure 11. $D$-values of the four samples under different stresses. (a) Sample I; (b) Sample II; (c) Sample III; (d) Sample IV.

Table 4. Fitting formulas for the $D$-value in terms of the stress.

\begin{tabular}{ccc}
\hline Samples & Fitting Formulas & Relative Coefficients $\left(\boldsymbol{R}^{\mathbf{2}}\right)$ \\
\hline I & $D=0.313 S^{2}-0.392 S+1.535$ & 0.882 \\
II & $D=0.042 S^{2}-0.118 S+1.445$ & 0.936 \\
III & $D=0.06 S^{2}-0.145 S+1.421$ & 0.913 \\
IV & $D=0.021 S^{2}-0.069 S+1.425$ & 0.949 \\
\hline
\end{tabular}

Therefore, a general quadratic polynomial can be used to describe the relationship between the $D$-values and stress of the tailings:

$$
D=a S^{2}-b S+c
$$

where $a\left(\mathrm{MPa}^{-2}\right), b\left(\mathrm{MPa}^{-1}\right)$ and $c$ are determined experimentally.

\subsection{Influence of Stress on the PSD of the Tailings}

The PSD parameters of the tailings after testing are presented in Table 5. Comparing with Table 2, the classifications of the four samples have not changed, but the characteristic particle sizes have decreased to various degrees. For example, the effective diameter, median diameter and control grain size of Sample IV have been reduced from 144.4, 385.8 and $457.4 \mu \mathrm{m}$ to $98.63,323.4$ and $389.2 \mu \mathrm{m}$, respectively, and the value of the effective diameter was reduced by $31.70 \%$. The PSDs of the 
four samples pre- and post-test are given in Table 6 . The quality percentages of particles smaller than a certain value post-test are greater than the pre-test values for all samples. In Sample IV, for example, the quality percentage of particles $<0.25 \mathrm{~mm}$ pre-test and post-test are $24.35 \%$ and $35.45 \%$, respectively, representing an increase of $45.59 \%$. The quality percentages of particles $<75 \mu \mathrm{m}$ of the four samples increase from $50.17,13.83,6.87$ and $5.52 \mu \mathrm{m}$ by $11.54,11.79,30.13$ and $116.67 \%$ to $55.96,15.46$, 8.94 and $11.96 \mu \mathrm{m}$, respectively, indicating that the quality percentages of fine tailings increase significantly, and the increase is more obvious for larger particles. This verifies that tailing particles are crushed under stress, and the degree of crushing increases with the particle size. These experimental results agree with the results of experiments on other granular materials [34].

Table 5. PSD parameters of the tailings post-test.

\begin{tabular}{|c|c|c|c|c|c|c|c|c|c|}
\hline $\begin{array}{l}\text { Sample } \\
\text { Number }\end{array}$ & $\begin{array}{l}\text { Effective } \\
\text { Diameter } \\
d_{10} / \mu \mathrm{m}\end{array}$ & $\begin{array}{l}\text { Median } \\
\text { Diameter } \\
d_{50} / \mu \mathrm{m} \\
\end{array}$ & $\begin{array}{l}\text { Control } \\
\text { Grain Size } \\
d_{60} / \mu \mathrm{m} \\
\end{array}$ & $\begin{array}{l}\text { Nonuniform } \\
\text { Coefficient } \\
C_{\mathrm{u}} \\
\end{array}$ & $\begin{array}{l}\text { Curvature } \\
\text { Coefficient } \\
C_{\mathrm{c}} \\
\end{array}$ & $\begin{array}{l}\text { Plastic } \\
\text { Limit } \\
P L / \% \\
\end{array}$ & $\begin{array}{l}\text { Liquid } \\
\text { Limit } \\
L L / \% \\
\end{array}$ & $\begin{array}{l}\text { Plastic } \\
\text { Index PI }\end{array}$ & Classification \\
\hline I & 7.14 & 61.83 & 83.75 & 11.73 & 1.42 & 17.8 & 26.7 & 8.9 & silt \\
\hline II & 40.07 & 206.9 & 248.5 & 6.20 & 1.49 & - & - & - & silty sand \\
\hline III & 84.95 & 297.1 & 343.5 & 4.04 & 1.33 & - & - & - & medium-sized sand \\
\hline IV & 98.63 & 323.4 & 389.2 & 3.95 & 1.24 & - & - & - & medium-sized sand \\
\hline
\end{tabular}

Table 6. PSDs of the tailings pre- and post-test.

\begin{tabular}{|c|c|c|c|c|c|c|c|c|}
\hline \multirow{2}{*}{ Sample } & & & \multicolumn{6}{|c|}{ Size (mm) } \\
\hline & & & $L \geq 0.25$ & $0.25>L \geq 0.125$ & $0.125>L \geq 0.075$ & $0.075>L \geq 0.018$ & $0.018>L \geq 0.01$ & $L<0.01$ \\
\hline \multirow{8}{*}{ Percent by weight (\%) } & \multirow{2}{*}{ I } & pre & 12.16 & 20.98 & 16.69 & 29.29 & 8.21 & 12.67 \\
\hline & & post & 3.75 & 23.2 & 17.09 & 33.8 & 9.42 & 12.74 \\
\hline & \multirow{2}{*}{ II } & pre & 46.56 & 29.39 & 10.22 & 9.76 & 2.77 & 1.3 \\
\hline & & post & 39.91 & 32.44 & 12.19 & 10.9 & 2.45 & 2.11 \\
\hline & \multirow{2}{*}{ III } & pre & 67.75 & 20.07 & 5.31 & 6.2 & 0.67 & 0 \\
\hline & & post & 59.98 & 22.08 & 9 & 5.58 & 1.84 & 1.52 \\
\hline & \multirow{2}{*}{ IV } & pre & 75.65 & 15.93 & 2.9 & 3.4 & 1.46 & 0.66 \\
\hline & & post & 64.55 & 17.91 & 5.58 & 6.33 & 2.45 & 3.18 \\
\hline
\end{tabular}

Note: $L=$ soil particle diameter.

\section{Discussion}

Tailing particles forming part of a tailing dam are subjected to compressive and shear stresses in the static dam itself and during flow when the tailing dam fails. Under these two stresses, deformations of the tailings' micro-structure could occur, including pore contracture, rotation of the particles' long axes to the best shear direction, particle slippage and particle crushing, as described in Section 4.3 and [35]. Fine tailings have been ground more thoroughly during mineral processing, making them nearly spherical. They can rotate, slip and move with little resistance without being crushed under stress. Conversely, coarse particles, which are much less regular and have high occlusal forces between them, will hardly rotate, slip or move unless they are crushed by the stress [36]. However, the force required to break particles is much greater than that required to rotate them [6]. Generally speaking, the strength of the tailings increases with the particle size [37], but this conclusion does not include the influence of 
the crushed particles on the PSD of the tailings in the compression test. However, this test has revealed an interesting result: the structural loading capacity of Sample IV is slightly less than that of Sample III, while the particle size of Sample IV is greater than that of Sample III, as shown in Section 4.1. The results of Section 4.4 show that tailing particles are crushed under stress and that the degree of crushing increases with the particle size, making the content of fine tailings increase observably and reducing the sample's loading capacity significantly.

The fractal dimension, based on the perimeter and area of the particles, is an important parameter for describing the architectural features of the tailings' particle shape, as shown in Section 4.1. Particle shape is widely considered one of the most important factors affecting the behavior of granular soils [38]. It has been proven that the fractal dimension describing the characteristics of the particle shape is significantly related to the strength characteristics of a soil [39]. However, particle breakage has a strong effect on the fractal dimension [40]. In addition, the particles' surface roughness decreases, and their shapes become more regular under shear stress [41,42]. Therefore, tailing particles become smaller and more regular under compressive and shear stresses, so their fractal dimension should decrease, in theory. In contrast, fine tailings are more hydrophilic due to their greater surface area, and their particles consequently cohere, forming agglomerates. During the process of image analysis, these agglomerates are regarded as a large "particles" with complex irregular shapes and greater $D$-values. Therefore, the $D$-value of fine tailings appears greater than that of coarse tailings, as shown by the $0 \%$ strain line in Figure 10. However, the $D$-value increases slightly with the particle size due to the crushing of coarse tailings under stress (Section 4.4), as is shown by the lines representing strains between $1.25 \%$ and $11.25 \%$ in Figure 10. In contrast, the agglomerates are dispersed under stress, and their shapes become more regular, reducing their $D$-values. However, the amount of agglomeration is limited, causing the decrease of the $D$-value to slow down as the stress increases, as shown in Figure 11. This phenomenon is in agreement with the results obtained in non-extensive statistical physics for similar experiments where fractal geometry is present [43] and with results on the planetary scale $[44,45]$.

The $D$-value of the particles' micro-structure not only reflects the characteristics of the PSD and particle geometry, but also represents the influence of pore water on the micro-structure's characteristics. This makes the $D$-value an important parameter for describing the characteristics of the tailings' micro-structure. Because the loading capacity of the tailings is significantly influenced by the PSD and the geometrical characteristics of the particles and pore water [46], the $D$-value has an inevitable internal connection with the loading capacity of the tailings. From the previous discussion, we can easily conclude that the deformation of the particles' micro-structure is well-described by the $D$-value, and a tailings dam break begins with the deformation of tailings. Therefore, a change in the $D$-value could be used to predict breaks in the tailing dam. In-depth studies are recommended to determine the mechanism connecting the macroscopic and microscopic mechanics of tailings to offer a reliable and useful approach to understanding the mechanism of tailing dam breaks.

\section{Conclusions}

The loading capacity characteristics of four different tailing samples with different particle sizes and the particles' micro-structural features were determined under one-dimensional compression. The tests 
were performed using a testing apparatus for micro-mechanics and the deformation of tailings. In addition, the particles' micro-structure was analyzed quantitatively using concepts from fractal geometry. The quantitative relationship between the $D$-value and axial stress was determined, along with the qualitative relationship between the $D$-value and particle size. Based on these results, the following conclusions can be drawn:

First, the particle size has a significant influence on the tailings' loading capacity, which increases significantly at first and then decreases slightly as the particle size increases. The slight decrease becomes more obvious under high axial strains. In contrast, the tailings' micro-structure changes significantly, and under stress, the particles can not only rotate to align themselves with the best shear direction, but can also be crushed. The latter is particularly true of coarse particles. Therefore, the tailings used for building dams should be made up of coarse particles to the greatest extent possible. The crushing of coarse particles under the pressure of overlying tailings layers is another important factor to consider when a tailing dam's stability is evaluated. The degree of crushing may be related to the formation stress, particle size and mineral properties, and further research should be conducted on the degree of crushing and its influence on dam stability.

Second, the particles' micro-structure is typical of fractals, and the fractal dimensions of the particle perimeter area ( $D$-values) of the four samples under different stresses are between 1.288 and 1.533. The $D$-value is closely related to the size of the particles in the tailings, and it first decreases and then increases slightly with the particle size. The decrease becomes smaller, and the increase becomes larger as the axial strain increases. The $D$-value tends to decrease with a few rebounds; the rate of decrease of the $D$-value dwindles; and the relationship between the $D$-value and the stress can be modeled by a quadratic polynomial. These results indicate that the $D$-value is an inherent attribute of the material described in this paper. These findings can effectively reflect the micro-structural characteristics and mechanical properties of tailings, which could contribute to research on the connection between the macroscopic and microscopic mechanics of tailings.

\section{Acknowledgments}

The financial support from National Natural Science Foundation of China (Grant Nos. 51304170 and 51074199), the Higher School Specialized Research Fund for the Doctoral Program Funding Issue (Grant No. 20110191110001), the National Key Basic Research and Development Program, (973 Program) China (Grant No. 2013CB228003), the Young Scholars Development Fund of SWPU (Southwest Petroleum University) (201231010031), the Special Fund of China's Central Government for the Development of Local Colleges and Universities, the Project of National First-level Discipline in Oil and Gas Engineering and the Ganpo (Jiangxi Province) 555 Elites Prize are appreciated.

\section{Author Contributions}

All of the authors were involved in the laboratory work, sample characterization, writing and revising of all parts of the manuscript. 


\section{Conflicts of Interest}

The authors declare no conflict of interest.

\section{References}

1. Shang, J.; Tang, M.; Miao, Z. Vacuum preload consolidation of reclaimed land: A case study. Can. Geotech. J. 1998, 35, 740-749.

2. Okagbue, C.O.; Yakubu, J.A. Limestone ash waste as a substitute for lime in soil improvement for engineering construction. Bull. Eng. Geol. Environ. 1999, 58, 107-113.

3. Eisazadeh, A.; Kassim, K.A.; Nur, H. Morphology and BET surface area of phosphoric acid stabilized tropical soils. Eng. Geol. 2013, 154, 36-41.

4. Yin, G.; Zhang, Q.; Wei, Z.; Jiang, C.; Wang, M.; Geng, W. Development and application of observation testing apparatus for micro-mechanics and deformation of tailings. Chin. J. Rock Mech. Eng. 2011, 30, 926-934. (In Chinese)

5. Jiang, M.; Zhang, F.; Hu, H.; Cui, Y.; Peng, J. Structural characterization of natural loess and remolded loess under triaxial tests. Eng. Geol. 2014, 181, 249-260.

6. Zhang, J.; Wang, R.; Zhang, Y.; Chen, F. Advance in studies of soil grain crush. Rock Soil Mech. 2003, 24, 661-665. (In Chinese)

7. Prosperini, N.; Perugini, D. Particle size distributions of some soils from the Umbria Region (Italy): Fractal analysis and numerical modeling. Geoderma 2008, 145, 185-195.

8. Tsallis, C. Introduction to Nonextensive Statistical Mechanics: Approaching a Complex World; Springer: New York, NY, USA, 2009; p. 14.

9. Perfect, E. Fractal models for the fragmentation of rocks and soils: A review. Eng. Geol. 1997, 48, $185-198$.

10. Giménez, D.; Perfect, E.; Rawls, W.J.; Pachepsky, Y. Fractal models for predicting soil hydraulic properties: A review. Eng. Geol. 1997, 48, 161-183.

11. Millán, H.; González-Posada, M.; Aguilar, M.; Domínguez, J.; Céspedes, L. On the fractal scaling of soil data: Particle-size distributions. Geoderma 2003, 117, 117-128.

12. Vallianatos, F.; Triantis, D.; Sammonds, P. Non-extensivity of the isothermal depolarization relaxation currents in uniaxial compressed rocks. Europhys. Lett. (EPL) 2011, 94, 68008, doi:10.1209/0295-5075/94/68008.

13. Vallianatos, F. On the non-extensive nature of the isothermal depolarization relaxation currents in cement mortars. J. Phys. Chem. Solids 2012, 73, 550-553.

14. Vallianatos, F.; Benson, P.; Meredith, P.; Sammonds, P. Experimental evidence of a non-extensive statistical physics behavior of fracture in triaxially deformed Etna basalt using acoustic emissions. Europhys. Lett. (EPL) 2012, 97, 58002, doi:10.1209/0295-5075/97/58002.

15. Vallianatos, F.; Triantis, D. Is pressure stimulated current relaxation in amphibolite a case of non-extensivity? Europhys. Lett. (EPL) 2012, 99, 18006, doi:10.1209/0295-5075/99/18006.

16. Vallianatos, F.; Michas, G.; Benson, P.; Sammonds, P. Natural time analysis of critical phenomena: The case of acoustic emissions in triaxially deformed Etna basalt. Phys. A Stat. Mech. Appl. 2013, 392, 5172-5178. 
17. Vallianatos, F.; Triantis, D. A non-extensive view of the Pressure Stimulated Current relaxation during repeated abrupt uniaxial load-unload in rock samples. Europhys. Lett. (EPL) 2013, 104, 68002, doi:10.1209/0295-5075/104/68002.

18. Marone, C.; Scholz, C. Particle-size distribution and micro-structures within simulated gouge. J. Struct. Geol. 1989, 11, 799-814.

19. Sammis, C.G.; Biegel, R.L. Fractals, fault-gouge, and friction. Pure Appl. Geophys. 1989, 131, $255-271$.

20. Ai, Y.; Chen, Z.; Guo, P.; Zeng, L.; Liu, H.; Da, Z.; Li, W. Fractal characteristics of synthetic soil for cut slope revegetation in the Purple soil area of China. Can. J. Soil Sci. 2012, 92, 277-284.

21. Buhl, E.; Kowitz, A.; Elbeshausen, D.; Sommer, F.; Dresen, G.; Poelchaud, M.H.; Reimold, W.U.; Schmitt, R.T.; Kenkmann, T. Particle size distribution and strain rate attenuation in hypervelocity impact and shock recovery experiments. J. Struct. Geol. 2013, 56, 20-33.

22. Vallejo, L.E.; Chik, Z. Fractal and laboratory analyses of the crushing and abrasion of granular materials. Geomech. Eng. 2009, 1, 323-335.

23. Yin, G.; Li, G.; Wei, Z.; Wan, L.; Shui, G.; Jing, X. Stability analysis of a copper tailings dam via laboratory model tests: A Chinese case study. Miner. Eng. 2011, 24, 122-130.

24. Yin, G.; Zhang, Q.; Wang, W.; Chen, Y.; Geng, W.; Liu, H. Experimental study on the mechanism effect of seepage on micro-structure of tailings. Saf. Sci. 2012, 50, 792-796.

25. Change, N.; Heymann, G.; Clayton, C. The effect of fabric on the behaviour of gold tailings. Géotechnique 2011, 61, 187-197.

26. Sun, X.; Wu, Z.; Huang, Y. Theory and Application of Fractal; University of Science and Technology Press: Beijing, China, 2003; pp. 39-41. (In Chinese)

27. Chen, Q. The perimeter-area fractal model and its application to geology. Math. Geol. 1995, 27, 69-82.

28. Mandelbrot, B.P. The Fractal Theory of Nature; Freeman: New York, NY, USA, 1983; pp. 25-48.

29. Imre, A.R.; Bogaert, J. The fractal dimension as a measure of the quality of habitats. Acta Biotheor. 2004, 52, 41-56.

30. Wang, B.; Shi, B.; Liu, Z.; Cai, Y. Fractal study on microstructure of clayey soil by GIS. Chin. J. Geotech. Eng. 2004, 26, 244-247. (In Chinese)

31. Yuan, J. Geotechnical Test and Its Principle; Tongji University Press Press: Shanghai, China, 2003; p. 109. (In Chinese)

32. Zhang, J. New advances in basic theories of sand dynamics. Chin. J. Geotech. Eng. 2012, 34, 1-50. (In Chinese)

33. Chen, R.; Lei, W.; Li, Z. Anisotropic shear strength characteristics of a tailings sand. Environ. Earth Sci. 2014, 71, 5165-5172.

34. Vesic, A.S.; Clough, G.W. Behavior of granular materials under high stresses. J. Soil Mech. Found. Div ASCE 1968, 94, 661-688.

35. Ghafghazi, M.; Shuttle, D.A.; DeJong, J.T. Particle breakage and the critical state of sand. Soils Found. 2014, 54, 451-461. 
36. Kjaernsli, B.; Sande, A. Compressibility of some coarsegrained materials. In Proceedings of the 1st European Conference on Soil Mechanics and Foundation Engineering, Weisbaden, Germany, 15-18 October 1963, pp.245-251.

37. Wei, Z.; Yin, G.; Li, G.; Wang, J.; Wan, L.; Shen, L. Reinforced terraced fields method for fine tailings disposal. Miner. Eng. 2009, 22, 1053-1059.

38. Goktepe, A.B.; Sezer, A. Effect of particle shape on density and permeability of sands. Proc. Inst. Civ. Eng. Geotech. Eng. 2010, 163, 307-320.

39. Bonala, M.; Reddi, P. Fractal representation of soil cohesion. J. Geotech. Geoenviron. Eng. 1999, 125, 901-904.

40. Taşdemir, A. Fractal evaluation of particle size distributions of chromites in different comminution environments. Miner. Eng. 2009, 22, 156-167.

41. Altuhafi, F.N.; Coop, M.R. The effect of mode of loading on particle-scale damage. Soils Found. 2011, 51, 849-856.

42. Miao, G.; Airey, D. Breakage and ultimate states for a carbonate sand. Géotechnique 2013, 63, 1221-1229.

43. Stergiopoulos, C.H.; Stavrakas, I.; Triantis, D.; Vallianatos, F.; Stonham, J. Predicting fracture of mortar beams under three-point bending using non-extensive statistical modeling of electric emissions. Phys. A Stat. Mech. Appl. 2015, 419, 603-611.

44. Vallianatos, F. On the non-extensivity in Mars geological faults. Europhys. Lett. (EPL) 2013, 102, 28006, doi:10.1209/0295-5075/102/28006.

45. Vallianatos, F.; Baziotis, I.; Udry, A.; Taylor, L.A. Application of non-extensive statistical physics on Martian nakhlites: A first-order approach on the crystal size distribution of pyroxene using Tsallis entropy. Europhys. Lett. (EPL) 2014, 108, 58002, doi:10.1209/0295-5075/108/58002.

46. Zhang, Q.; Yin, G.; Chen, Y.; Geng, W.; Wang, W. Experimental Study on the Affecting Factors of the Shear Strength of Unsaturated Tailings. In Proceedings of 2011 International Symposium on Water Resource and Environmental Protection; Chang'an University Press: Xi'an, China, 2011; Volume 1, pp. 89-93.

(C) 2015 by the authors; licensee MDPI, Basel, Switzerland. This article is an open access article distributed under the terms and conditions of the Creative Commons Attribution license (http://creativecommons.org/licenses/by/4.0/). 